\title{
School burnout and engagement in the context of demands-resources model
}

\author{
Katariina Salmela-Aro ${ }^{1,2 *}$ and Katja Upadyaya ${ }^{3}$ \\ 'University of Helsinki, Finland \\ ${ }^{2}$ University of Jyväskylä, Finland \\ ${ }^{3}$ University of Michigan, Ann Arbor, Michigan, USA
}

Background. A four-wave longitudinal study tested the demands-resources model in the school context.

Aim. To examine the applicability of the demands-resources to the school context.

Method. Data of I,709 adolescents were gathered, once during the transition from comprehensive to post-comprehensive education, twice during post-comprehensive education, and once 2 years later.

Results. The hypotheses were supported, path analysis showing that study demands were related to school burnout a year later, while study resources were related to schoolwork engagement. Self-efficacy was positively related to engagement and negatively to burnout. School burnout predicted schoolwork engagement negatively I year later. Engagement was positively related to life satisfaction 2 years later, while burnout was related to depressive symptoms. Finally, burnout mediated the relationship between study demands and mental health outcomes.

Conclusions. The demands-resources model can usefully be applied to the school context, including the associations between school-related burnout and engagement among adolescents. The model comprises two processes, the energy-depleting process and the motivational process.

Engagement with schoolwork is vital to a student's educational success and development into a competent member of society (Ryan \& Patrick, 2001). Researchers, educators, and policy makers are increasingly focusing on student engagement as a means of addressing problems of student boredom and alienation, low achievement, and high dropout rate, as it offers several benefits for research and practice (Fredricks, Blumenfeld, \& Paris, 2004). Students who are more engaged with school earn higher grades and show better personal adjustment to school and beyond. Conversely, students who are burned out by school are more likely to experience academic failure, school dropout, and a host of other negative psychosocial outcomes (Salmela-Aro, Savolainen, \& Holopainen, 2009). These

*Correspondence should be addressed to Katariina Salmela-Aro, Helsinki Collegium for Advanced Studies, P.O. Box 4, FIN-000 I 4, University of Helsinki, Helsinki, Finland (email: katariina.salmela-aro@helsinki.fi). 


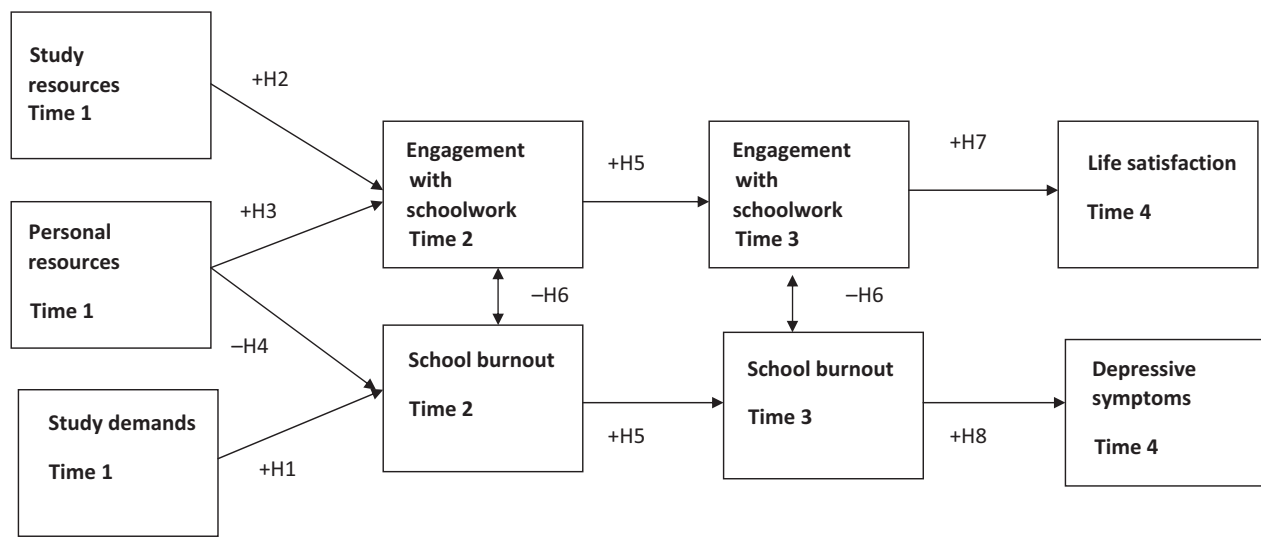

\begin{tabular}{|llll|}
\hline $\begin{array}{l}\text { Age } 15 \\
\text { Comprehensive school }\end{array}$ & Age 16 & Age 17 19 \\
& Secondary education & & Age 19 \\
\hline
\end{tabular}

Figure I. Hypothesized path model. Time I = comprehensive school, Time 2 = I year later in post-comprehensive education, Time $3=2$ years later in post-comprehensive education, Time $4=2$ years later. $+=$ positive, $-=$ negative.

engagement and burnout processes are typically studied separately, but the framework of the demands-resources model - usually applied to occupational fields - highlights the importance of investigating them as parallel processes (Demerouti, Bakker, Nachreiner, \& Schaufeli, 2001). Moreover, application of the model has been of interest to educational psychology in the context of teacher and student well-being and achievement (e.g., Klusmann, Kunter, Trautwein, Lüdtke, \& Baumert, 2008). However, this is the first longitudinal study to examine the applicability of the demands-resources model to the school context using four-wave longitudinal data, including the associations between adolescent school-related burnout and engagement (see Figure 1).

\section{Burnout and engagement with schoolwork}

School provides an important developmental context for adolescents (Eccles, 2004). Previous research has shown that student perceptions and experiences of school are associated with various adjustment outcomes. Although many concepts, such as low academic achievement and motivation, poor self-esteem, school stress and tiredness, and internal and external problem behaviours (Byrne, Davenport, \& Mazanov, 2007), have been used to describe maladjustment at school, only a few studies have been carried out on burnout and stress specifically at school. School burnout has been defined as exhaustion due to study demands, a cynical attitude towards school, and feelings of inadequacy as a student (Salmela-Aro, Kiuru, Leskinen, \& Nurmi, 2009).

School engagement research also has a long tradition (Newmann, 1991; Skinner, Wellborn, \& Connell, 1990) and has typically been described in terms of a multidimensional construct including affective, cognitive, and behavioural components (Appleton, Christenson, Kim, \& Reschly, 2006; Fredricks et al., 2004). Recent studies in the field have shown that engagement with schoolwork can also be defined as an overall concept that 
comprises energy, dedication, and absorption in schoolwork (Salmela-Aro, Kiuru, Leskinen, \& Nurmi, 2009; Salmela-Aro \& Upadyaya, 2012; Schaufeli, Martinez, Pinto, Salanova, \& Bakker, 2002). Energy can be defined as a positive approach to studying, characterized by high levels of vigour and mental resilience while studying, and a willingness to apply oneself. Dedication, in turn, is manifested in a positive cognitive attitude towards studying in general, interest in one's academic work and seeing it as meaningful, being intimately involved in one's studies, and experiencing a sense of significance, enthusiasm, inspiration, pride, and challenge. Finally, absorption refers to feelings of competence and success, as well as behavioural accomplishment, both in one's studies and in school as a whole. The relations between school-related burnout and engagement have seldom been analysed. The assumption has been that burnout and engagement are independent but negatively associated (Kiuru, Nurmi, Aunola, \& Salmela-Aro, 2009; Schaufeli \& Bakker, 2004), although the cross-lagged longitudinal relationships between burnout and engagement in the school context have not hitherto been examined.

\section{Demands-resources model}

The relatively new job demands-resources (JD-R) model of occupational stress (Demerouti et al., 2001; Schaufeli \& Bakker, 2004) assumes that the characteristics of environments can usually be divided into two categories: demands and resources (e.g., Demerouti et al., 2001; Llorens, Bakker, Schaufeli, \& Salanova, 2006). Demands require physical and/or psychological effort and consequently are related to physiological and/or psychological costs (i.e., strain). Resources, in turn, are features that are functional in achieving work goals, reducing the demands and the physical and/or psychological costs associated with them, and stimulating personal growth and development (e.g., Schaufeli \& Bakker, 2004). The demands-resources model assumes two processes (Demerouti et al., 2001): (1) an effort-driven energetic process of overtaxing and wearing out, in which heavy demands exhaust energy and lead to burnout and, later, diminished mental health; and (2) a motivational process in which the lack of sufficient resources precludes dealing effectively with heavy demands, leading to disengagement and fostering mental withdrawal. Recent work-related studies have revealed the positive impact of job resources on work engagement and subsequent performance and of job demands on work burnout (Bakker \& Demerouti, 2007, 2008). Personal resources that refer to personenvironment interplay, such as self-efficacy beliefs, have recently been added to the model. Recent studies have shown that personal resources such as self-efficacy explain why job resources are translated into work engagement (Xanthopoulou, Bakker, Demerouti, \& Schaufeli, 2009).

However, less is known about the extent to which the demands-resources model can be applied to the school context. In academic settings, students encounter many different study demands and resources, which may later be manifested in their level of engagement and burnout at school, as well as in their overall well-being. Moreover, to gain a deeper understanding of these processes, it is important to study them in parallel, including both the effort-driven and motivational processes in the same model (Demerouti et al., 2001). This was done in the present study, in which demands are seen as presenting a challenge to study-related goals, while resources are seen as functional in achieving study-related goals. In addition, self-efficacy beliefs were added to the model. Study resources and high self-efficacy may promote student engagement in schoolwork, while study demands might lead to feelings of burnout. In line with the demands-resources model, 
study-related resources rather than demands would constitute more robust determinants of engagement with schoolwork, while study demands would constitute determinants of school burnout. For example, study-related stress can be interpreted as a demand felt by students that they adjust to school, whereas high self-efficacy may function as a resource for their engagement with school (Vasalampi, Salmela-Aro, \& Nurmi, 2010). We expect a high level of study demands to be related to school burnout and both study and personal resources to be related to engagement with schoolwork. Burnout and engagement are expected to be independent but negatively associated (Kiuru et al., 2009; Schaufeli \& Bakker, 2004). However, we cannot set a hypothesis as the cross-lagged longitudinal relationships between burnout and engagement in the context of school have not been examined previously.

Later adjustment: Depressive symptoms and life satisfaction

According to the JD-R model, burnout increases later ill-being, such as depressive symptoms (Hakanen, Bakker, \& Schaufeli, 2006). Previous studies in the work context have revealed that burnout and depressive symptoms are associated (Schaufeli \& Bakker, 2004). When burnout and depression have been examined as concepts, both similarities and differences have been noted (Iacovides, Fountoulakis, Kaprinis, \& Kaprinis, 2003; McKnight \& Glass, 1995). Furthermore, mental health has been shown to deteriorate as burnout advances (Golembiewski, Lloyd, Scherb, \& Munzenrider, 1992). Moreover, because the more severe burnout is, the closer it is qualitatively to depression (Iacovides et al., 2003), burnout, and depression might develop 'in tandem' (McKnight \& Glass, 1995). In the school context, it has been found that stressful experiences at school and the emotions they generate may predict depressive symptoms (Ge, Lorenz, Conger, Elder, \& Simons, 1994). Previous research suggests that school burnout is positively associated with depression (state and trait) and negatively with engagement and self-esteem (Fimian \& Cross, 1986; Salmela-Aro, Kiuru, et al., 2009). Burnout at school has also been linked with tedium, poor quality of school life, external locus of control, self-handicapping, and avoidant achievement strategies (Covington, 2000; Fimian \& Cross, 1986). A recent longitudinal study revealed that school burnout predicted depressive symptoms more strongly than vice versa (Salmela-Aro, Savolainen, et al., 2009). A fundamental distinction between the two concepts of burnout and depressive symptoms is that school burnout is supposedly school related, whereas depression is expected to be more pervasive in nature and multifactorial in origin (Salmela-Aro, Kiuru, et al., 2009). In the school context, in a cross-sectional study, confirmatory factor analyses showed that the items of the school burnout and depressive symptom scales did not load on the same factor (Salmela-Aro, Kiuru, et al., 2009).

The JD-R suggests that model engagement should lead to well-being, in the form of life satisfaction, defined as an individual's overall appraisal of the quality of his or her life (Diener, Emmons, Larsen, \& Griffin, 1985), including the perception of progressing towards important life goals (Diener, Suh, Lucas, \& Smith, 1999). Shin and Johnson (1978) defined life satisfaction as a global assessment of a person's quality of life according to his or her chosen criteria, while Frisch (2000) defined it as a person's subjective evaluation of the degree to which his or her most important needs, goals, and wishes have been fulfilled. The demands-resources model led us to expect that engagement with schoolwork would be related to later life satisfaction (Salmela-Aro \& Tuominen-Soini, 2010). Because the demands-resources model includes two processes - the energy-depleting process of 
gradually wearing out and the motivational process of study-goal attainment - we hypothesized that engagement would mediate the relationship between study resources and life satisfaction, while school burnout would mediate the relationship between study demands and mental health outcomes in terms of depressive symptoms.

\section{Aims and hypotheses}

The aim of the present four-wave longitudinal study was to test the demands-resources model in the school context (see Figure 1). We hypothesized that heavy study demands would be positively related to later school burnout (H1), while high study resources would be related to later engagement in schoolwork (H2). In addition, we assumed that personal resources (self-efficacy) would be positively related to engagement with schoolwork (H3) and negatively related to school burnout (H4). Engagement and burnout at school were assumed to be stable (H5) and negatively associated (H6). We also examine the cross-lagged paths between engagement and burnout in the context of schoolwork but, as this is the first study to examine this question, no hypothesis was proposed. Moreover, we hypothesized that engagement in schoolwork would be positively related to later life satisfaction $(\mathrm{H} 7)$, while burnout at school would be related to later depressive symptoms (H8). The model includes two processes: the energy-depleting process of gradually wearing out and the motivational process of study-goal attainment. We finally hypothesized that engagement would mediate the relationship between study resources and life satisfaction (H9), while school burnout would mediate the relationship between study demands and mental health outcomes (H10).

\section{Method}

\section{Data source and sample}

The data for this study were drawn from the FinEdu study. Ninth-grade students were followed up twice - after the transition to post-comprehensive education and 2 years thereafter. In Finland, all adolescents have a similar basic general education up to age 16 (comprehensive school). After comprehensive school, 55\% enter upper secondary school and $37 \%$ vocational school. Both upper secondary school and vocational school take 34 years to complete. High academic achievement in the ninth grade is required for admission to upper secondary school. Upper secondary school education, in turn, is a prerequisite for university education, whereas vocational school education leads directly to a lower occupational qualification. A total of 1,709 adolescents ( 856 girls, 853 boys) from 9 comprehensive schools, and later on from 13 post-comprehensive schools (six upper secondary schools; seven vocational schools), participated in the study. The transition to and from the post-comprehensive schools meant that the number of the participants varied more at the beginning and at the end of the study. Thus, at the first (Time 1) and the last (Time 4) measurement times, there were fewer participants ( $N=642$ and $N=611$ respectively), as all the students participated in the study during their post-comprehensive education even if they were not present at the outset. The student participation rate in the schools ranged between $65 \%$ and $100 \%$, with an average of $84 \%$. The adolescents completed a questionnaire four times: once at the end of their ninth grade (Time 1: study demands and resources), once during the first (age 16) and second (age 17) years of their post-comprehensive school (Time 2 and Time 3: 
engagement and burnout), and once 2 years after the start of their post-comprehensive education (age 19) (Time 4: depressive symptoms and life satisfaction).

At Time 1 , the participants' median age was 15 years $(M=15.47 ; S D=1.73)$. The majority (99\%) were Finnish speaking, one per cent of them having some other mother tongue. This is broadly in line with the figures for ethnic minorities at the national level. The occupational distribution was as follows: $27 \%$ of the fathers and $20 \%$ of the mothers of the participants worked in higher white-collar occupations, $16.4 \%$ of fathers and $49 \%$ of mothers worked in lower white-collar occupations, 36\% of fathers and $17 \%$ of mothers worked in blue-collar occupations, $11 \%$ of fathers and $4 \%$ of mothers were private entrepreneurs, $1 \%$ and $2 \%$ were students, $3 \%$ and $2 \%$ were retired, and $5 \%$ and $6 \%$ had some other status (such as unemployed). Questionnaires (Time 1-Time 3) were group administered to the students in their classrooms during regular school hours, and at Time 4 , they were mailed to the participants.

\section{Measures}

Study demands, study resources, and personal resources

The participants were asked at Time 1 to evaluate their study-related personal goal (Vasalampi et al., 2010): To what extent have you progressed towards achieving this goal? (study resources, three questions), How challenging is this goal? (study demands, two questions), and How efficacious do you feel in choosing a proper educational path for yourself? (personal resources, six questions). Items were rated using a 7-point Likert scale ranging from 1 (not at all) to 7 (completely). For a similar procedure, see Vasalampi et al. (2010).

Schoolwork engagement inventory (Salmela-Aro \& Upadyaya, 20I2)

Engagement with schoolwork was measured at Time 2 and Time 3 by the abbreviated student version of the Utrecht Work Engagement Scale, the UWES-9 (Schaufeli, Bakker, \& Salanova, 2006) based on the Utrecht Work Engagement Scale, UWES-S developed by Schaufeli et al. (2002). The scale consists of nine items measuring energy (e.g., When I study, I feel that I am bursting with energy), dedication (e.g., I am enthusiastic about my studies), and absorption (e.g., Time flies when I'm studying) in relation to schoolwork. Responses were rated on a 7-point scale ranging from 0 (not at all) to 7 (daily). Cronbach's alpha for overall engagement was .90 and .92.

School burnout was measured at Time 2 and Time 3 by the School Burnout Inventory (Salmela-Aro, Kiuru, et al. 2009; Salmela-Aro, Savolainen, et al. 2009). The inventory comprises nine items measuring three factors of school burnout: (1) exhaustion at school (i.e., I feel overwhelmed by my schoolwork); (2) cynicism about the meaning of school (i.e., I feel lack of motivation in my schoolwork and often think of giving up); and (3) sense of inadequacy as a student (i.e., I often bave feelings of inadequacy in my schoolwork) to be rated on a 6-point scale $(1=$ strongly disagree; $6=$ strongly agree $)$. Cronbach's alpha for overall school burnout was .94 and .90.

Depressive symptoms were measured at Time 4 using the Finnish Depression Scale (DEPS-10; Salokangas, Stengård, \& Poutanen, 1994). The scale consists of 10 questions, drawn from the Hopkins checklist, on the participant's mood over the last month (e.g., I felt sad; I felt my future was bopeless). The student responses were rated on a 4-point scale ranging from 1 (not at all) to 4 (very much). Cronbach's alpha for the scale was .92. A total score based on the mean of the ratings was computed. 
Life satisfaction was assessed at Time 4 using the five-item Satisfaction with Life Scale (Diener et al., 1985). The items (e.g., I am satisfied with my life) were rated on a 7-point scale ranging from 1 (I totally disagree) to 7 (I totally agree). A sum score was calculated from all five items. Cronbach's alpha was .90.

\section{Demographics}

Gender was coded by asking the adolescents to circle the correct alternative $(1=$ girl, 2 = boy). School track was coded as follows: upper secondary school students were coded 1 and vocational school students were coded 0 .

\section{Analytical strategy}

Path analyses with regression coefficients were used to investigate the model. The statistical analyses were performed using the Mplus statistical package (version 6; Muthén \& Muthén, 1998-2012) with a missing-data method. This method uses all the data available to estimate the model without imputing the data. The parameters of the models were estimated using the maximum-likelihood robust (MLR) estimation method, which is robust to non-normality of the observed variables. Goodness of fit was evaluated using the following three absolute goodness-of-fit indices: (1) chi-squared test; (2) root mean square error of approximation (RMSEA); and (3) standardized root mean square residual (SRMR). Because the chi-squared test is sensitive to sample size, the use of relative goodness-of-fit indices is also strongly recommended in the case of large sample sizes (Bentler \& Bonett, 1980). Consequently, the following relative goodness-of-fit indices were also used to evaluate model fit: (1) the Comparative Fit Index (CFI) and (2) the Tucker-Lewis Index (TLI). Finally, Akaike's information criterion (AIC) indices of the alternative models were obtained.

\section{Results}

Table 1 shows the means, variances, and correlations. To address the research questions, a path model was constructed. Study resources, personal resources, and study demands at Time 1 (ninth grade) were first included in the model as antecedents for the schoolwork engagement and burnout variables measured at Time 2 and Time 3. Second, the tested model included stability coefficients for schoolwork engagement and burnout, their intercorrelations, and the cross-lagged paths between them. Finally, life satisfaction and depressive symptoms at Time 4 were included as consequences of engagement and school burnout. In addition, the concurrent path between life satisfaction and depressive symptoms was added. The results showed that after omitting all the non-significant paths, the model fitted the data well: $\chi^{2}(19, N=1,686)=46.70, p<n s$, CFI $=.98$, TLI $=.96$, RMSEA $=.03$, and SRMR $=.05$. The results in Figure 2 show, first, that both study resources and personal resources at Time 1 positively predicted subsequent engagement with schoolwork at Time 2 . Both resources also negatively predicted subsequent school burnout symptoms at Time 2 . In turn, study demands at Time 1 positively predicted study burnout symptoms at Time 2 .

Second, both school burnout and engagement showed moderate stability. Moreover, the cross-lagged paths between study burnout and engagement showed that it was student school burnout (Time 2) that negatively predicted their later engagement with 


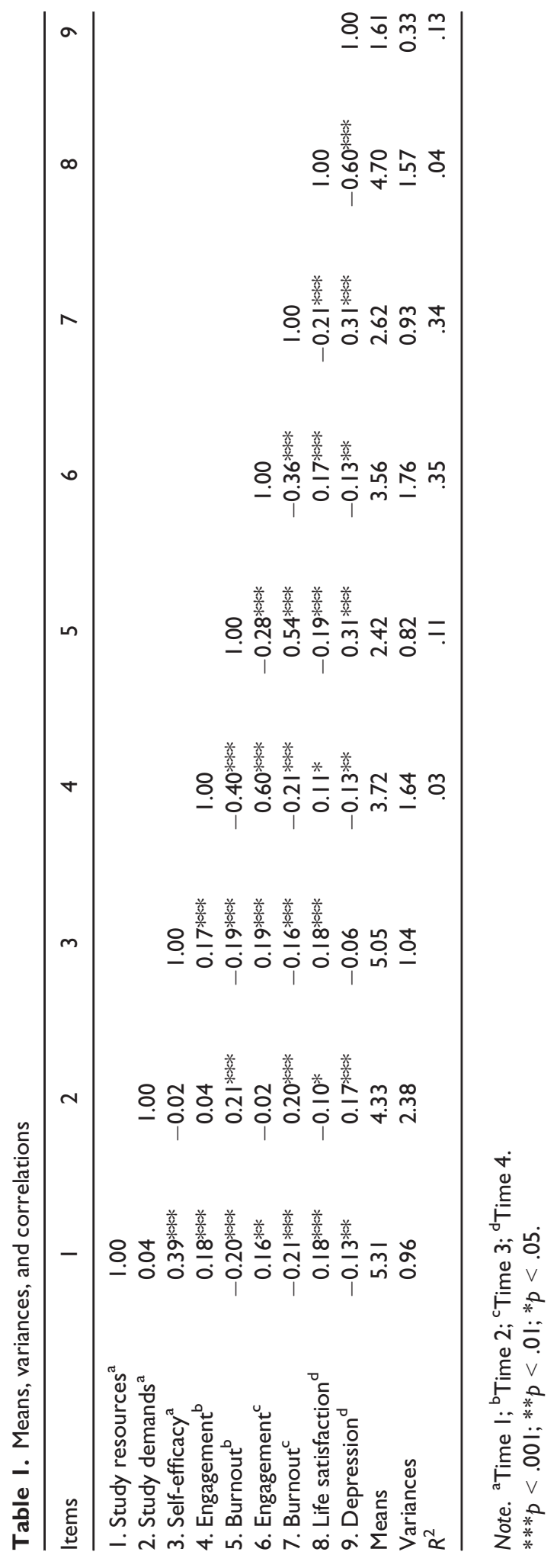




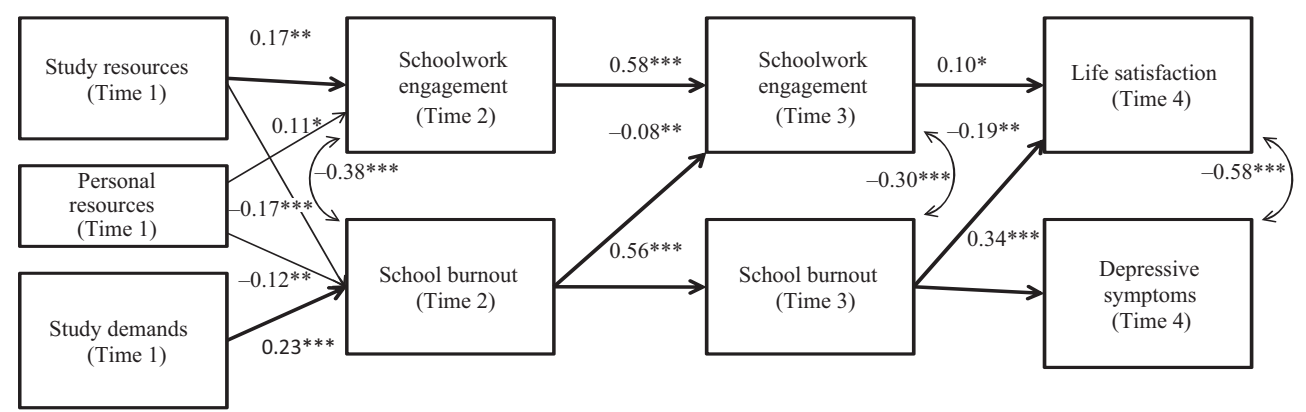

Figure 2. The standardized estimates for the demands-resources model in the school context. Note. ${ }^{*} p<.05 ; * p<.01 ; * * p<.001$.

schoolwork (Time 3) rather than vice versa: the more the symptoms related to burnout the students reported, the lower their subsequent engagement with schoolwork.

Third, engagement with schoolwork positively predicted subsequent life satisfaction 2 years later (Time 4 ), and school burnout symptoms negatively predicted subsequent life satisfaction during the second year of post-comprehensive education (Time 3). In turn, school burnout symptoms (Time 3 ) positively predicted subsequent depressive symptoms 2 years later (Time 4).

Next, to test the mediation effects of study resources on engagement and life satisfaction and of study demands on burnout and mental health (hypotheses H9 and H10), a similar model, including direct paths from personal and study resources to life satisfaction and a path from study demands to depressive symptoms, was tested. The final model fitted the data well: $\chi^{2}(18, N=1,686)=35.38, p<n s$, CFI $=.99$, TLI $=.98$, RMSEA $=.02$, and SRMR $=.04$. In this model, all the previous results remained the same, except that the path from engagement at Time 3 to life satisfaction at Time 4 was not significant. Instead, self-efficacy (Time 1) directly predicted students' life satisfaction (Time $4 ; B=0.14, p<.001$ ). Similarly, study demands (Time 1 ) positively predicted their depressive symptoms (Time $4 ; B=0.08, p<.05$ ).

Next, the size and significance of the indirect (mediated) effect from study demands through burnout to mental health were examined using bias-corrected, bootstrapped confidence intervals with 1,000 resamples (Lau \& Cheung, 2010). This technique allowed us to calculate empirically derived standard errors for all the model parameters, including indirect effects. The asymmetric 95\% confidence interval derived from the bootstrapping procedure was examined to determine whether the indirect effect was statistically significant by observing whether the $95 \%$ confidence interval included zero. The results showed that the $95 \%$ confidence interval for the indirect effect was between 0.01 and 0.02 and that the confidence interval for the difference between the direct and indirect effects was between -0.02 and 0.05 , suggesting that the specific mediation effect from study demands to burnout and further to depressive symptoms was not significantly different from the direct effect.

\section{Gender and school track}

To determine whether the final model would be different for boys and girls and for students on the vocational versus academic track, all the analyses were also conducted using the multigroup procedure (Jöreskog \& Sörbom, 1993). In these analyses, the data 
were divided into two samples (e.g., boys and girls, or students on the vocational and academic track). Path analyses were carried out on the assumption that all the paths of the final model were equal for the various subgroups. If the fit of the model is good and no significant modification indices are found, the model is assumed to fit the subgroups equally. These analyses showed that the final model fitted the data for boys and girls equally - and also the data for students on the vocational and academic tracks.

\section{Discussion}

The present four-wave longitudinal study investigated the demands-resources model in the school context. Using the JD-R model as a guiding framework, we documented pathways from study demands and resources to later schoolwork-related engagement and burnout and to later life adjustment in a sample of students during their transition from comprehensive to post-comprehensive education. Our results showed that the model fitted the data well and can thus be used as a theoretical background for burnout and engagement in the school context. The demands-resources model assumes two processes (Demerouti et al., 2001): an effort-driven energetic process of overtaxing and wearing out in which severe study demands exhaust the student's energy and lead first to burnout and then to diminished mental health, for example, in the form of depression. The other is a motivational process in which the availability of resources leads to engagement and fosters life satisfaction.

Supporting our hypothesis (H1), study demands in the last year of comprehensive school were positively related to school burnout in upper secondary education 1 year later, while (H2) study resources were positively related to engagement with schoolwork 1 year later. In addition, personal resources in the last year of comprehensive school were positively related to engagement with schoolwork $(\mathrm{H} 3)$ and negatively to school burnout $(\mathrm{H} 4) 1$ year later. Engagement with schoolwork and school burnout were both stable during upper secondary education (H5) and negatively associated (H6). The cross-lagged paths between engagement with schoolwork and school burnout revealed that school burnout negatively predicted engagement with schoolwork 1 year later. Next, supporting our hypothesis (H7), engagement with schoolwork was positively related to life satisfaction 2 years later, while (H8) school burnout was positively related to depressive symptoms. School burnout was also negatively related to life satisfaction 2 years later. Our results thus indicate that the demands-resources model is a suitable framework for explaining student pathways to adjustment and maladjustment in the school context and general adjustment later on. The model includes both an effort-driven energetic process of overtaxing and wearing out in which great demands exhaust energy and lead to burnout and diminished mental health and a motivational process in which the availability of resources leads to engagement.

The present study found support for the two processes of the demands-resources model (Demerouti et al., 2001) in the school context. However, our hypothesis (H9) was not supported. Schoolwork engagement did not mediate the relationship between study resources and life satisfaction. Our results revealed that personal resources predicted life satisfaction. However, the other mediation hypothesis (H10) was supported: school burnout mediated the relationship between study demands and mental health outcomes. Overall, a particularly strong relationship existed between the negative variables between study demands and school burnout and between burnout and depressive symptoms. In contrast, the paths between the positive variables from study resources to engagement and from engagement to life satisfaction were weaker, and the cross-lagged 
paths from study resources to burnout and from burnout to life satisfaction weaker still. Supporting the model, the cross-lagged paths to engagement from demands and from engagement to depressive symptoms were not statistically significant. This agrees well with the energetic effort-related process - from study demands to burnout and later to depressive symptoms - and the motivation process - from study resources to engagement and later to satisfaction with life. This supports recent findings in the work context (Bakker, van Veldhoven, \& Xanthopoulou, 2010; Hakanen, Schaufeli, \& Ahola, 2008). As triggers of the motivational process, study resources increase schoolwork engagement which in turn is associated with positive outcomes later on. In turn, the mental health impairment process is an energy draining process from study demands to depressive symptoms mediated by school burnout.

The results showed that school burnout and engagement with schoolwork can be studied by means of the demands-resources model. In the first segment of the model, the basic assumption is that the school environment can be divided into study-related demands and resources. Study demands require effort from the student to achieve study-related goals. Consistent with the model, the results showed that demanding study-related goals are related to later school burnout. In addition, these demands might have been intensified in the present study, as the students were facing the critical transition from general comprehensive school to academic and vocational educational education. Moreover, the results suggest that high study demands in comprehensive school can lead to poorer adjustment and increase burnout symptoms of later educational settings. Future studies should include a variety of study demands, such as study overload, in addition to study-related emotional demands. Study resources, on the other hand, are features that are functional in achieving study-related goals. Consistent with the model, the results also show that achieving study-related goals is related to later engagement with schoolwork. Moreover, the results suggested that study resources at comprehensive school support engagement with subsequent studies in both upper secondary and vocational education. In addition, according to the model, study demands result in strain reactions, while lack of resources hinders goal accomplishment, resulting in feelings of frustration and failure. Such feelings are likely to cause withdrawal behaviour and depressive symptoms later on. This study provided support for the model by showing that study resources were more robustly related to engagement with schoolwork than study demands, which in turn impaired psychological health by increasing school burnout. Moreover, in addition to study resources, personal resources in terms of self-efficacy were added to the model. Personal resources refer to person-environment interplay and may pertain to a specific domain, for example, study-related self-efficacy. A key attribute of personal resources is that they facilitate goal attainment in the face of adversity (Van den Heuvel, Demerouti, Schaufeli, \& Bakker, 2010). The results showed that personal resources in comprehensive school supported engagement in subsequent studies and hindered the level of subsequent burnout symptoms. These results are in line with the demands-resources model according to which high personal resources lead to motivational processes. In addition, our study showed the important role of personal resources in explaining why study resources translate into engagement with schoolwork. Future studies should include a greater variety of study resources, such as support from others, to investigate these processes further. In addition, as recently suggested by Bakker (2011), it might be that engagement is also a predictor of later study and personal resources. This is an opportunity for future research.

Furthermore, as expected, in the second segment of the model, engagement with schoolwork and school burnout - examined here for the first time together - were found 
to be negatively related: the results of the cross-lagged longitudinal path analysis showed that school burnout negatively predicted later engagement with schoolwork. This is an important new finding, revealing the important role of school burnout for later decrease in engagement with schoolwork. Finally, in support of the demands-resources model, engagement with schoolwork was found to lead to well-being in terms of life satisfaction, whereas school burnout was found to predict later ill-being in the form of depressive symptoms, also corroborating earlier results (Salmela-Aro, Kiuru, et al. 2009; Salmela-Aro, Savolainen, et al. 2009). In the school context, an earlier cross-sectional study showed that school burnout and depressive symptoms are separate concepts (Salmela-Aro, Savolainen, et al. 2009). Finally, engagement with schoolwork positively predicted later life satisfaction. The concept of life satisfaction includes the perception that one is progressing towards important life goals (Diener et al., 1999). Recent reviews (Gilman \& Huebner, 2003; Huebner, 2004) have highlighted the importance of life satisfaction in the positive adjustment of adolescents, while knowledge on how engagement with schoolwork predicts later life satisfaction during adolescence has remained lacking. The present study filled this gap by showing that engagement with schoolwork positively predicted life satisfaction among late adolescents and young adults, while school burnout predicted it negatively. Finally, the results show that both adjustment and maladjustment in the school context can subsequently spill over to other life domains. This is an important finding, indicating that the school setting can play a crucial role in preventing depressive symptoms and promoting life satisfaction.

In the present study, the demands-resources model was also tested for different subgroups according to the gender and the type of the post-comprehensive education. The results showed that the model fitted the data sets well, which supported the application of the demands-resources model in the school context. Our study demonstrates that negative psychological states (i.e., school burnout) and positive psychological states (i.e., engagement) play similar roles in quite different processes. Personal resources seem to be related to both processes. Based on the results, both reducing heavy study demands and promoting both study-related and personal resources are important for later adjustment.

The results, showing that academic well-being in terms of high engagement and low burnout can play a crucial role for overall well-being later on, have several implications for practice. Preventing burnout and promoting engagement in the school setting can play a key role in supporting young people's well-being. The results also reveal the crucial role of resources for academic well-being. Students should receive positive feedback at school, as this would help promote their efficacy beliefs and engagement.

This study contributes to the growing field of pedagogical and academic well-being research. In the OECD context, it has been suggested that one of the key goals of education is the cultivation, not of proficiency alone but also of engagement (OECD, 2010). The challenge is to find ways of fostering active engagement opportunities and providing impetus for all students, in particular for those at risk of learning or motivational problems or marginalization. Teachers have an important role in shaping young people's engagement in education through the emotional, instructional, and organizational support embedded in classroom processes. However, while efforts to reform the learning environments of young people need to be based on up-to-date evidence-based information on the facilitators of engagement, they also need to be supported by a wide range of stakeholders. 


\section{Limitations}

The study has the following main limitations. First, in future research, a full panel design could be used to examine the demands-resources model in the school context. In addition, this study examined the extent to which the demands-resources model was applicable to the school context. In future, plausible alternative models should be tested. Third, more research is needed in the middle and high school, university and vocational school settings. Further studies are also needed to examine the role of engagement and burnout across an extended period of time. Fourth, the study was conducted in Finland, and thus, one must be cautious about generalizing the results to school contexts in other countries. However, many European countries have a similar educational system, in which students attend comprehensive school and then proceed to upper secondary school or vocational school and later to university. In addition, this study was based on self-reports. It should be borne in mind that compared to work settings, school offers fewer opportunities to make choices and decisions than work. However, post-secondary educational institutions offer students more autonomy. Next, study demands and resources were studied with just one item. Future research would need better scales. Finally, studies that include the present model should also include other resources and demands as well as other outcomes. Additional research in this area is clearly warranted.

\section{Conclusions}

The demands-resources model, which includes two processes - energy-depleting and motivational - can usefully be applied to the school context, including the associations between school-related burnout and engagement among adolescents.

\section{Acknowledgement}

We acknowledge support from the Academy of Finland 134931, 139168 and the Jacobs Foundation.

\section{References}

Appleton, J. J., Christenson, S. L., Kim, D., \& Reschly, A. L. (2006). Measuring cognitive and psychological engagement: Validation of the student engagement instrument. Journal of School Psychology, 44, 427-445. doi:10.1016/j.jsp.2006.04.002

Bakker, A. B. (2011). An evidence-based model of work engagement. Current Directions in Psychological Science, 20, 265-269. doi:10.1177/0963721411414534

Bakker, A. B., \& Demerouti, E. (2007). The job demands-resources model: State of the art. Journal of Managerial Psychology, 22, 309-328. doi:10.1108/02683940710733115

Bakker, A. B., \& Demerouti, E. (2008). Towards a model of work engagement. Career Development International, 13, 209-223.

Bakker, A. B., van Veldhoven, M., \& Xanthopoulou, D. (2010). Beyond the demand-control model. Journal of Personnel Psychology, 9, 3-16.

Bentler, P. M., \& Bonett, D. G. (1980). Significance tests and goodness of fit in the analysis of covariance structures. Psychological Bulletin, 88, 588-606.

Byrne, D. G., Davenport, S. C., \& Mazanov, J. (2007). Profiles of adolescent stress: The development of the adolescent stress questionnaire (ASQ). Journal of Adolescence, 30, 393-416. doi:10.1016/j.adolescence.2006.04.004 
Covington, M. (2000). Goal theory, motivation, and school achievement: An integrative review. Annual Review of Psychology, 51, 171-200. doi:10.1146/annurev.psych.51.1.171

Demerouti, E., Bakker, A. B., Nachreiner, F., \& Schaufeli, W. B. (2001). The job demands-resources model of burnout. Journal of Applied Psychology, 86, 499-512. doi:10.1037/0021-9010.86.3. 499

Diener, E., Emmons, R. A., Larsen, R. J., \& Griffin, S. (1985). The satisfaction with life scale. Journal of Personality Assessment, 49, 71-75. doi:10.1207/s15327752jpa4901_13

Diener, E., Suh, E. M., Lucas, R. E., \& Smith, H. L. (1999). Subjective well-being: Three decades of progress. Psychological Bulletin, 125, 276-302. doi:10.1037/0033-2909.125.2.276

Eccles, J. S. (2004). Schools, academic motivation, and stage-environment fit. In R. M. Lerner \& L. D. Steinberg (Eds.), Handbook of adolescent psychology (pp. 125-153). Hoboken, NJ: Wiley.

Fimian, M., \& Cross, A. (1986). Stress and burnout among preadolescent and early adolescent gifted students: A preliminary investigation. The Journal of Early Adolescence, 6, 247-267. doi: $10.1177 / 0272431686063004$

Fredricks, J. A., Blumenfeld, P. C., \& Paris, A. H. (2004). School engagement: Potential of the concept, state of the evidence. Review of Educational Research, 74, 59-109. doi:10.3102/ 00346543074001059

Frisch, M. B. (2000). Improving mental and physical health care through quality of life therapy and assessment. In E. Diener \& D. R. Rahtz (Eds.), Advances in quality of life theory and research (pp. 207-241). Dordrecht, the Netherlands: Kluwer Academic Press.

Ge, X., Lorenz, F. O., Conger, R. D., Elder, G. H., \& Simons, R. L. (1994). Trajectories of stressful life events and depressive symptoms during adolescence. Developmental Psychology, 30, 467-483. doi:10.1037/0012-1649.30.4.467

Gilman, R., \& Huebner, E. S. (2003). A review of life satisfaction research with children and adolescents. School Psychology Quarterly, 18, 192-205. doi:10.1007/s10964-006-9036-7

Golembiewski, R. T., Lloyd, M., Scherb, K., \& Munzenrider, R. F. (1992). Burnout and mental health among police officers. Journal of Public Administration Research and Theory, 2, 424-439.

Hakanen, J., Bakker, A. B., \& Schaufeli, W. B. (2006). Burnout and engagement among teachers. Journal of School Psychology, 43, 495-513. doi:10.1016/j.jsp.2005.11.001

Hakanen, J., Schaufeli, W. B., \& Ahola, K. (2008). The Job Demands-Resources model: A three-year cross-lagged study of burnout, depression, commitment and work engagement. Work \& Stress, 22, 224-241. doi:10.1080/02678370802379432

Huebner, E. S. (2004). Research on assessment of life satisfaction of children and adolescents. Social Indicators Research, 66, 3-33. doi:10.1023/B:SOCI.0000007497.57754.e3

Iacovides, A., Fountoulakis, K. N., Kaprinis, S., \& Kaprinis, G. (2003). The relationship between job stress, burnout and clinical depression. Journal of Affective Disorders, 75, 209-221. doi:10.1016/S0165-0327(02)00101-5

Jöreskog, K. G., \& Sörbom, D. (1993). LISREL8: Structural equation modelling with the SIMPLIS command language. Hillsdale, $\mathrm{NJ}$ : Erlbaum.

Kiuru, N., Nurmi, J.-E., Aunola, K., \& Salmela-Aro, K. (2009). Peer group homogeneity in adolescents' school adjustment varies according to peer group type and gender. International Journal of Behavioral Development, 33, 65-76. doi:10.1177/0165025408098014

Klusmann, U., Kunter, M., Trautwein, U., Lüdtke, O., \& Baumert, J. (2008). Engagement and emotional exhaustion in teachers: Does school context make a difference? Health and Well-Being, 57, 127-151. doi:10.1111/j.1464-0597.2008.00358.x

Lau, R. S., \& Cheung, G. W. (2010). Estimating and comparing specific mediation effects in complex latent variable models. Organizational Research Methods, 15, 3-16. doi:10.1177/ 1094428110391673

Llorens, S., Bakker, A. B., Schaufeli, W. B., \& Salanova, M. (2006). Testing the robustness of the Job Demands-Resources model. International Journal of Stress Management, 13, 378-391. doi:10.1037/1072-5245.14.2.224 
McKnight, J. D., \& Glass, D. C. (1995). Perceptions of control, burnout, and depressive symptomatology: A replication and extension. Journal of Consulting and Clinical Psychology, 63, 490-494. doi:10.1037/0022-006X.63.3.490

Muthén, L., \& Muthén, B. O. (1998-2012). Mplus users guide \& Mplus. Version 5.0. Retrieved from http://www.statmodel.com/index $2 . h t m l$

Newmann, F. (1991). Student engagement in academic work: Expanding the perspective on secondary school effectiveness. In J. R. Bliss \& W. A. Firestone (Eds.), Rethinking effective schools: Research and practice (pp. 58-76). Englewood Cliffs, NJ: Prentice Hall.

OECD. (2010). PISA 2009 Assessment Framework Key competencies in reading, mathematics and science. Paris, France: OECD.

Ryan, A., \& Patrick, H. (2001). The classroom social environment and changes in adolescents' motivation and engagement during middle school. American Educational Research Journal, 38, 437-460. doi:10.3102/00028312038002437

Salmela-Aro, K., Kiuru, N., Leskinen, E., \& Nurmi, J.-E. (2009). School Burnout Inventory: Reliability and validity. European Journal of Psychological Assessment, 25, 48-57. doi:10.1027/ 1015-5759.25.1.48

Salmela-Aro, K., Savolainen, H., \& Holopainen, L. (2009). Depressive symptoms and school burnout during adolescence: Evidence from two cross-lagged longitudinal studies. Journal of Youth and Adolescence, 38, 1316-1327. doi:10.1007/s10964-008-9334-3

Salmela-Aro, K., \& Tuominen-Soini, H. (2010). Adolescents' life satisfaction during the transition to post-comprehensive education: Antecedents and consequences. Journal of Happiness Studies, 11, 683-701. doi:10.1007/s10902-009-9156-3

Salmela-Aro, K., \& Upadyaya, K. (2012). The schoolwork engagement inventory: Energy, dedication and absorption (EDA). European Journal of Psychological Assessment, 28, 60-67. doi:10.1027/1015-5759/a000091

Salokangas, R. K. R., Stengård, E., \& Poutanen, O. (1994). DEPS - Uusi väline depression seulontaan [DEPS. An instrument for screening depression]. Duodecim, 110, 1141-1148.

Schaufeli, W. B., \& Bakker, A. B. (2004). Job demands, job resources and their relationship with burnout and engagement: A multi-sample study. Journal of Organizational Behavior, 25, 293 299. doi: 10.1002/job. 248

Schaufeli, W. B., Bakker, A. B., \& Salanova, M. (2006). The measurement of work engagement with a short questionnaire: A cross-national study. Educational and Psychological Measurement, 66, 701-716. doi:10.1177/0013164405282471

Schaufeli, W. B., Martinez, I., Pinto, A. M., Salanova, M., \& Bakker, A. B. (2002). Burnout and engagement in university students: A cross-national study. Journal of Cross-Cultural Psychology, 33, 464-481. doi:10.1177/0022022102033005003

Shin, D., \& Johnson, D. (1978). Avowed happiness as an overall assessment of the quality of life. Social Indicators Research, 5, 475-492. doi:10.1007/BF00352944

Skinner, E. A., Wellborn, J. G., \& Connell, J. P. (1990). What it takes to do well in school and whether I've got it: The role of perceived control in children's engagement and school achievement. Journal of Educational Psychology, 82, 22-32. doi:10.1037/0022-0663.82.1.22

Van den Heuvel, M., Demerouti, E., Schaufeli, W. B., \& Bakker, A. B. (2010). Personal resources and work engagement in the face of change. In J. Houdmont \& S. Leka (Eds.), Contemporary occupational health psychology (pp. 124-150). West Sussex, UK: John Wiley \& Sons.

Vasalampi, K., Salmela-Aro, K., \& Nurmi, J.-E. (2010). Education-related goal appraisals and self-esteem during the transition to secondary education: A longitudinal study. International Journal of Behavioral Development, 34, 481-490. doi:10.1177/0165025409359888

Xanthopoulou, D., Bakker, A. B., Demerouti, E., \& Schaufeli, W. B. (2009). Reciprocal relationships between job resources, personal resources and work engagement. Journal of Vocational Behavior, 74, 235-244. doi:10.1016/j.jvb.2008.11.003

Received 27 July 20 I I; revised version received 4 March 2013 